\title{
LA HABANA: JÓVENES, BARRIOS E IDENTIDAD. APUNTES DESDE LA INVESTIGACIÓN SOCIAL
}

\author{
ANA ISABEL PEÑATE LEIVA* \\ DALGIS LÓPEZ SANTOS ${ }^{* *}$
}

\begin{abstract}
RESUMEN
El artículo que se presenta considera algunos de los resultados de la investigación: «Identidad juvenil en diferentes barrios de la Ciudad de La Habana», realizada por las autoras en el año 2007 y que constituye el segundo resultado del proyecto: «Territorio e identidad juvenil en Ciudad de La Habana». En estas páginas, el lector podrá acercarse a algunas de las características identitarias que distinguen a los jóvenes que viven en cinco barrios tradicionales de la capital cubana, con características propias y diferentes por su nivel socioeconómico: Náutico, Pogolotti, Jesús María, Guaicanamar y La Víbora. Estos barrios comparten, como regularidad, una determinada estabilidad en el tiempo y en la población que habita en ellos, lo que de alguna manera condiciona los resultados obtenidos, que quizás en otros barrios un poco más inestables o con flujos más intensos, se muestren diferentes. Sin embargo, el punto de partida lo constituye un breve recorrido por el proceso de conformación de la nación y la nacionalidad cubana así como, una mirada puntual a la historia de los cinco barrios estudiados.
\end{abstract}

PALABRAS CLAVE: CUBA, HISTORIA, IDENTIDAD JUVENIL

* Licenciada en Historia; Master en Sexualidad; Diplomada en Desarrollo Humano Local, Género e Infancia. Investigadora Auxiliar y Subdirectora del Centro de Estudios Sobre la Juventud. Coordinadora General de la Revista Estudio y profesora de la Universidad de La Habana.

E-mail: jfalcon@inder.cu.

** Licenciada en Psicología, Diplomada en Trabajo Social. Investigadora del Centro de Estudios Sobre la Juventud y profesora de la Universidad de La Habana. E-mail: cestinv@jovenclub.cu. 


\title{
HAVANA: JOVENS, BAIRROS E IDENTIDADE. APONTAMENTOS A PARTIR DA PESQUISA SOCIAL
}

\begin{abstract}
RESUMO
Este artigo apresenta alguns resultados da pesquisa: «Identidade juvenil em diferentes bairros da Cidade de Havana», realizada pelas autoras no ano de 2007 e que constitui o segundo resultado do projeto: «Território e identidade juvenil na Cidade de Havana». Nestas páginas, o leitor poderá conhecer algumas características identitárias que diferenciam os jovens que vivem em cinco bairros tradicionais da capital cubana, com características próprias e diferentes por seu nível socioeconômico: Náutico, Pogolotti, Jesús María, Guaicanamar y La Víbora. Estes bairros compartilham regularmente de certa estabilidade no tempo e na população que neles habita, o que de alguma maneira condiciona os resultados obtidos. Talvez em outros bairros um pouco mais instáveis ou com fluxos mais intensos, os resultados seriam diferentes. O ponto de partida é uma breve retomada do processo de estruturação da nação e a nacionalidade cubana, bem como um olhar pontual na história dos cinco bairros estudados.
\end{abstract}

PALAVRAS-CHAVE: CUBA, HISTÓRIA, IDENTIDADE JUVENIL

\section{HAVANA: YOUTH, IDENTITY BARRIERS, NOTES FROM SOCIAL RESEARCH}

\begin{abstract}
The present article considers some of the results of the investigation: «Youth Identity in different neighborhoods of the City of Havana», conducted by the authors in 2007 and is the second output of the project: «Territory and youth identity in Havana». In these pages the reader can approach some of the identity characteristics that distinguish youth living in five traditional districts of the Cuban capital, with its own characteristics and different in socioeconomic status: Náutica, Pogolotti, Jesús María, Guaicanamar and La Víbora. These districts commonly share a certain stability over time and the people living in them, which somehow determines the results, perhaps in other quarters a little more unstable or more intense flows, show different. However, the starting point is a brief tour of the forming process of the $\mathrm{Cu}-$ ban nation and nationality as well as a timely look at the history of the five districts which have been studied.
\end{abstract}




\section{CUBA, CUBANOS E IDENTIDAD. APUNTES HISTÓRICOS}

¿QUIÉNES SOMOS? ESTA INTERROGANTE pudiera ser considerada como el punto de partida en cualquier estudio sobre identidad. Sin embargo, responder a ella necesariamente exige un análisis de un tiempo anterior que se traduce en un ¿de dónde venimos? La relación que se establece entre pasado y presente, permite una proyección de futuro: ¿hacia dónde vamos? Ello corrobora afirmaciones realizadas por disímiles autores acerca de lo identitario como proceso continuo y a la vez cambiante.

La identidad se crea. La identidad se recibe y se forma. Se transmiten nociones, valores históricos, memoria, representaciones, rasgos, costumbres, que tienden a perdurar y a mantener lo mejor de la identidad. Eso nunca ocurre de manera invariable. La identidad se recibe y cada generación la recrea, la elabora, la enriquece (De la Torre, 2001:191).

El proceso de reconocerse diferente o semejante a otros, y con esto autodefinirse, es un ejercicio que ha acompañado al género humano en todo su progreso, lo que junto a su labor creadora, ha contribuido a la conformación de un sentimiento de pertenencia a diferentes grupos en todas las escalas (familia, barrio, nación, generación...), y como proceso social, se sujeta a un contexto histórico determinado, que acentuará o no las características del mismo.

Es importante en la construcción de identidades sociales el espacio no sólo físico, sino social, en el que interactúan los sujetos sociales. En tal espacio social, que es revitalizado por quienes lo habitan y frecuentan, se desarrollan las relaciones cotidianas de los individuos y las grupalidades. Éstos, de acuerdo a las exigencias que enfrentan con su realidad, tratan de encontrar un lugar propio que pueden reconocer y que les sea reconocido, para desde allí reestructurar cotidianamente su visión del mundo y su relación con él (Marcial, 1996:42).

Proponemos, entonces. un breve recorrido histórico por el tratamiento que en el saber político y de los científicos sociales de Cuba, se ha manejado sobre la identidad del cubano en los diferentes contextos. Visto de otra manera, podríamos referir que estamos tras la búsqueda de la conformación de la cubanidad, la cual, al decir del eminente etnólogo Fernando Ortíz, 
no está solamente en el resultado, sino también en el mismo proceso complejo de su formación, desintegrativo e integrativo, en los elementos sustanciales que entran en su acción, en el ambiente en que se opera y en las vicisitudes de su transcurso (Barrial, 1991:11).

Si bien es cierto que el siglo XIX cubano resulta trascendental en la historia posterior de la nación, no es posible omitir la relevancia de un conjunto de hechos acontecidos entre los siglos XVI y XVIII. En este período «se asientan los estratos profundos, los componentes sociales y humanos, que van a servir de definición y diferenciación de la sociedad criolla (1545-1697) y la de su consolidación (1607-1762)» (Torres y Loyola, 2001:73-74).

Para Cuba, su historia escrita comienza hace más de quinientos años con el arribo del almirante Cristóbal Colón a sus costas en 1492. Constituye esto un primer momento en el proceso de construcción de nuestra identidad cuando contactan, se enfrentan y se funden una cultura aborigen autóctona, cuyo estadio de desarrollo no rebasa la Comunidad Primitiva y la cultura europea, en transición de la época medieval a la de la acumulación originaria de capital. Las primeras expresiones de resistencia ante un poder impuesto desde fuera, provienen de esta época.

La organización de la colonia se centró en la creación de villas. Con ello se perseguía,

crear una base legal organizativa y política en cada región lo cual se lograba al establecer, en cada acto de fundación, la institución del municipio, [...] garantizar la concentración y permanencia en el territorio de un núcleo conquistador mediante la vecindad. Esta última institución es de primerísima importancia en la colonización española porque transforma al conquistador en vecino que se compromete a permanecer en el territorio como vía para adquirir sus derechos dentro de la institución municipal. La vecindad permitió la presencia de un número estable de pobladores en los primeros años que, con el tiempo, dio origen a un nuevo arquetipo social, el criollo, cuyos nexos estarían ya definitivamente vinculados con su región (Torres y Loyola, 2001:52).

El componente racial marca la identidad del cubano. La población nativa recibe el impacto - brutal — de la colonización blanca europea. La presencia negra se hace sentir desde el primer momento, aunque de manera limitada; su irrupción a gran escala en la isla, tiene que ver con el fenómeno de la trata de esclavos y su utilización como fuerza 
de trabajo, básicamente en las plantaciones de caña. Para el siglo XIX, y vinculada también a la economía, comienza la introducción en el país de los llamados chinos culíes y los oriundos de la península de Yucatán. Esta confluencia racial dio lugar a un profundo proceso de mestizaje presente en nuestra cultura y nacionalidad.

Es válido precisar, que no es posible percibir homogeneidad en estos grupos raciales. Por ejemplo, la inmigración española no sólo puede ubicarse como la fuerza colonizadora con poder económico, sino que también hubo una masa proveniente de diferentes regiones de España que llegó a la isla contratada para asumir actividades relacionadas con el comercio, la agricultura (no de plantación), la administración y la vida militar. Entre ellos, y partiendo de su región de origen, existían marcadas diferencias sociales. Veamos: los canarios no eran considerados españoles, su destino fue la colonización de tierras del interior de la isla, lo que los llevó a convertirse en campesinos. Los castellanos por su parte, se ubicaban en el aparato administrativo y militar en las ciudades, mientras que los catalanes se ocupaban del comercio.

Dentro de la inmigración europea, a la altura del siglo XIX, hallamos los blancos provenientes de Francia, asentados fundamentalmente en la zona centro-oriental del país. Introdujeron nuevas técnicas en el cultivo del café y el cacao, e hicieron sustanciales aportes a la cultura. «La orquesta de la contradanza francesa será la base de la evolución de nuestras orquestas típicas» (Torres y Loyola, 2001:108).

Respecto a los chinos, si bien los culíes entraban al país en condiciones de semiesclavitud, destinados a zonas agrícolas, hubo otra corriente proveniente de California.

Estos inmigrantes disponían de ciertos recursos económicos e, independientemente de su origen en China, tenían ya una cultura comercial y productora que los diferenciaba de la inmigración esencialmente campesina que provenía directamente del país asiático [...] La presencia de esta población en todos los sectores productivos y de servicios (sobre todo como agricultores, cocineros, dulceros, panaderos, jardineros, vendedores ambulante, etc.) le imprimió a la sociedad cubana rasgos que se conservan como parte de sus hábitos, costumbres y tradiciones (Torres y Loyola, 2001:161).

Con relación a los negros, ha existido la tendencia de verlos como un todo, sin considerar su diversidad étnica, lo que implica culturas diferentes. Como elemento que le otorga a la inmigración negra un fondo 
común, se halla el área geográfica de procedencia que comprende, fundamentalmente, la zona costera del África Occidental hasta el sur de Angola. Este proceso de lo común y lo diferente y su interrelación con el blanco, origina determinadas particularidades que han trascendido como lo afrocubano:

Así, el componente negro de la cultura y la sociedad cubanas, no será, en el decurso del tiempo, el resultado de la permanencia de las multiculturas africanas sino que constituirá en sí mismo una manifestación cultural nueva; distinta, en primer lugar de los diferentes elementos africanos originales, y de todos en su conjunto y, en segundo lugar, integrado, interactuado e interdependiente de la evolución de la cultura del blanco que, a su vez también se transforma de lo español a lo criollo (Torres y Loyola, 2001:64-65).

Criollo es la denominación que reciben los nacidos en Cuba después del proceso de colonización y que se convirtieron en el elemento de mismidad de nuestra identidad, visualizando la otredad en sus progenitores que inmigraron a la isla. Es la convergencia de culturas, costumbres, tradiciones y comportamientos que responden a la satisfacción de sus necesidades espirituales y materiales desde una nueva manera de sentir, actuar y decir.

La arquitectura es otro elemento que incide en la identidad. Para el caso específico de La Habana, es la época de construcción de sus grandes fortificaciones defensivas: los Castillos de la Real Fuerza, San Salvador de la Punta y los Tres Reyes del Morro; suntuosos palacetes como casas viviendas o con fines públicos y ahí están por ejemplo el Palacio Aldama y el de los Capitanes Generales y los paseos como la Alameda de Paula, punto de intensa vida social para el habanero. Incidirá también la fundación aquí de la Real y Pontificia Universidad de San Jerónimo de La Habana y la publicación de obras como La Historia de la Isla y Catedral de Cuba, como expresión de una intelectualidad emergente que persigue contribuir en la formación de la memoria histórica.

La Habana quedó dividida en dos: intra y extramuros, como expresión del poder económico y la diferenciación social y de clases. Los pobres a los barrios marginales fuera de la muralla; las clases alta y media desarrollaron su vida toda al interior de la ciudad amurallada. Pregones, mercados y el típico cañonazo que aún retumba en las noches habaneras, vienen de esta época. 
Aportarán a este proceso de formación y consolidación de la identidad, acontecimientos internacionales como la Revolución de las 13 colonias norteamericanas, expresión de las contradicciones antagónicas entre metrópoli y colonia; realidad que vivía Cuba en sus nexos con España y la revolución ocurrida en Haití y liderada por negros.

Desde el punto de vista ideológico, el criollo asumirá diferentes corrientes que transitan desde posiciones conservadoras como el autonomismo o reformismo, y que no se pronuncian por un rompimiento definitivo con el poder colonial; posiciones anexionistas que tienen su punto de mira en los Estados Unidos y apoyan la política expansionista de éste, hasta posiciones más radicales que apuntan hacia la abolición de la trata y la independencia nacional, la que ya no dejará de estar presente en la identidad del cubano y hace posible entonces que valoraciones como las de Fernando Ortiz nos ayuden en ese bregar incansable en la respuesta al quiénes somos:

La cubanía, que es conciencia, voluntad y raíz de la patria, surgió primero en la gente aquí nacidas y crecidas, sin retorno ni retiro, con el alma arraigada a la tierra. La cubanía fue brotada desde abajo y no llovida desde arriba (Ortiz, en Barreal, 1991:12).

\section{IDENTIDAD, JÓVENES Y TERRITORIO}

Desde hace algunos años, la capital cubana se encuentra inmersa en el Programa Territorial de Investigaciones Sociales: «La identidad en Ciudad de La Habana», rectorado por la Delegación Provincial del Ministerio de Ciencia, Tecnología y Medio Ambiente (CITMA) y el Comité Provincial del Partido, con el propósito explícito de contribuir a un mejor conocimiento de la realidad del territorio y diseñar estrategias más efectivas de desarrollo económico y social en la ciudad. Dentro de este programa, la cuestión juvenil constituye en sí misma tema de investigación. El proceso de identidad en la juventud y la formación de las nuevas identidades, da cabida a las diferentes propuestas realizadas por los centros de estudios e investigaciones, relacionadas con los jóvenes capitalinos. Así surgió el proyecto cuyos resultados socializamos en el presente artículo: «Territorio e identidad juvenil en Ciudad de La Habana».

Partimos entonces de algunos presupuestos para sustentar la trilogía: identidad, jóvenes y territorio. Así tenemos que la identidad es aprehendida a través de la práctica social, por lo que la instrucción de 
conocimientos, los hábitos, costumbres, cualidades, las relaciones interpersonales, los vínculos productivos, culturales, las normas de conducta, las concepciones estéticas y del mundo en general, que se forman a través de la familia, la escuela, la comunidad, los grupos informales, centros laborales y medios de comunicación masiva, son elementos que ejercen gran influencia en la construcción social de las características identitarias. Ahora bien, esas características no son iguales para todos los grupos humanos que conviven en un mismo medio social; sino que tienen sus matices a partir del sexo, la edad, la región, el color de la piel, la religión, entre otros indicadores. Estas microidentidades son factores que juegan un papel determinante en el mantenimiento de la identidad nacional y cultural. La identificación de las personas con su generación y más específicamente con sus edades y peculiaridades del desarrollo, es uno de los cimientos para la construcción de identidades cuya influencia en la cultura y la nacionalidad es fundamental.

En este sentido, resulta vital el estudio de las características identitarias de los jóvenes como grupo etáreo, pues estos pueden constituirse como agentes de cambio de una realidad condicionada por la historia y las herencias del pasado, modificando e imponiendo nuevas formas de identificación que pudieran ser en beneficio de los valores y principios que ha defendido y defiende la sociedad en que se vive, o en detrimento de los mismos. La historia ha demostrado que la generación joven es portadora del cambio y el progreso de las sociedades, que en sí misma contiene la mezcla de lo tradicional y lo innovador y abre las puertas hacia las transformaciones graduales de valores sociales, éticos, morales, de costumbres y creencias, culturas, posicionamientos de género y revoluciones políticas.

Para nuestra realidad es importante tener presente que el joven del que hablamos hoy, no es precisamente aquel que se formó en medio de la lucha por la independencia de la nación y que vivenció el triunfo y las primeras transformaciones de la Revolución; momentos claves, que junto a otros, sintetizan los orígenes de nuestra sociedad actual. Es justamente aquel que nació con el surgimiento y/o profundización de estos problemas y para los cuales, el conocimiento relativo a la formación de nuestra nacionalidad y el sistema político y social de Cuba, son sólo los recuerdos de sus abuelos, los que constantemente se entremezclan con las experiencias actuales de una sociedad en proceso de construcción, que defendiendo sus principios, se enfrenta a una «invasión» de imágenes, representaciones y significados transmi- 
tidos por un mundo globalizado, consumista y neoliberal. De ahí que, entre la juventud cubana coexistan diversos modelos de identidad, con los cuales se conforman sentidos de pertenencias que se expresan en los discursos y comportamientos juveniles. Consideramos además, que los estudios sobre identidad juvenil realizados en Cuba hasta la fecha, aún no son suficientes para entender el complejo proceso identitario en general, y de este grupo etáreo en particular. A eso añadimos la necesidad de realizar investigaciones a partir de ejes transversales que permitan desentrañar identidades en contextos específicos.

Justamente uno de esos ejes es el territorio. Aún cuando todos los jóvenes pertenezcan a la misma provincia, sus vidas cotidianas no transitan en todo este espacio, sino que se concentra en localidades definidas por municipios, comunidades y barrios, que actúan como resortes de identidad.

Para los jóvenes el lugar donde vive no se percibe únicamente como un espacio funcional de residencia o de socialización, sino como espacio de interacciones afectivas y simbólicas, un espacio cargado de sentidos. Lo anterior se puede apreciar en el sentido que se atribuye a la calle, las plazas, que muchas veces aparecen como escenarios para la expresión de la cultura que producen en una reconsideración del espacio [...] Podemos afirmar que la cultura juvenil transforma los espacios físicos en sociales mediante producción de estructuras particulares de significados (Dayrell, 2005:141).

Uno de los espacios territoriales más complejos en la conformación de la identidad es precisamente el designado como metrópolis de un país. La complejidad estriba en las disímiles influencias internas y externas que se producen en las capitales, debido a procesos migratorios, económicos y de aperturas culturales. En Cuba, si queremos descubrir las identidades juveniles de los capitalinos para — desde la diversidadintentar fomentar la identidad del habanero, debemos considerar todos estos elementos. Desde esta perspectiva, podemos contribuir a identificar el entramado de significaciones acerca de quiénes somos, hacia dónde nos dirigimos y qué queremos, así como la pertenencia a determinados grupos, lo cual sería de gran ayuda para la consolidación de nuestros valores y sentimientos de nación. 


\section{IDENTIDAD JUVENIL EN DIFERENTES BARRIOS DE LA CAPITAL CUBANA}

La investigación se realizó en cinco barrios de igual cantidad de municipios de la capital cubana, los que fueron seleccionados a partir de considerar tres propuestas que los clasifican. Por un lado, la tipología de municipios que propone la doctora Luisa Iñiguez, ${ }^{1}$ y que explica la reestructuración de los asentamientos poblacionales y las ciudades que antes de la División Política Administrativa de 1976 se insertaban en la provincia de La Habana y que después de esa fecha, pasaron a conformar la Ciudad de la Habana. ${ }^{2}$ Dentro de esa tipología, fueron seleccionados los municipios con mayor y menor concentración juvenil, comprendida en el rango de edades entre 15 y 29 años, a partir de los datos ofrecidos por la Oficina nacional de estadísticas. Por último, se tuvo en cuenta la clasificación para la determinación de los niveles sociales globales de calidad de vida de los municipios de la capital, contenidos en el estudio: «Componentes socioestructurales y distancias sociales en la ciudad».

Estaremos hablando entonces de las características identitarias de los jóvenes de los barrios: Náutico, Pogolotti, La Víbora (alta concentración juvenil), Jesús María y Guaicanamar (baja concentración juvenil), ubicados en los municipios: Playa, Marianao, 10 de Octubre, Habana Vieja y Regla respectivamente. Todos estos territorios son reconocidos por la población como barrio tradicional, con características propias y diferentes por su nivel socioeconómico; comparten, como regularidad, una determinada estabilidad en el tiempo y en la población que habita en ellos, lo que de alguna manera condiciona los resultados obtenidos, que quizás en otros barrios un poco más inestables o con flujos más intensos, se muestren diferentes.

\section{a) Pequeñas historias barriales}

NÁUTiCo: al oeste de la Ciudad de La Habana, entre las aguas del río Quibú, la costa norte y la $5^{\mathrm{a}}$ Avenida, se encuentra enclavado el

1 Investigadora del Centro de Desarrollo y Bienestar Humano de la Universidad de la Habana. Dirige el Proyecto: «Diferenciación espacial e identidades en Ciudad de La Habana. Contextos y escenarios».

2 En Cuba, las provincias se dividen en municipios, por ejemplo, la Ciudad de La Habana está conformada por 15 municipios. Así mismo, por la División Política Administrativa de 1976 el país, dividido históricamente en seis provincias, pasó a tener 14 provincias y un Municipio Especial. 
reparto residencial Náutico. Este barrio surge a principios de la década del 50 de la pasada centuria, cuando comienza a parcelarse el terreno y se inicia su venta para la edificación de viviendas. En esta parcelación, se aplican principios básicos de lo que en la arquitectura moderna se denomina «condominios residenciales» incluso, se habla de que este fue el primer intento de este tipo de construcción en Latinoamérica.

Hay un elemento interesante en el surgimiento de este barrio, y es su asociación con la ampliación y remodelación del otrora Club Náutico de Marianao del cual además, toma su nombre, colindante con el también muy conocido Casino Español de La Habana. ${ }^{3}$ Inicialmente, existía una única vía peatonal para llegar a ambos clubes, pero entre 1950 y 1952 se crean accesos independientes para uno y otro centro y, justamente, la ruta para llegar al Club Náutico atravesará el espacio donde más tarde se construirá el barrio.

Otro elemento importante tiene que ver con sus primeros pobladores. En el imaginario social del habanero, o para ser más exactos, de muchos residentes en la capital, el Reparto Náutico siempre ha sido un barrio de personas de un nivel socioeconómico alto y muy alto. Sin embargo, vale hacer algunas precisiones. La mayor parte de los asociados del Club Náutico pertenecían a la clase media baja y era más común que las clases media y alta pertenecieran al Casino Español. Precisamente, son los socios del Náutico quienes básicamente compran terrenos para levantar sus viviendas, muchas de ellas con habitaciones independientes para ser alquiladas en los meses de verano, lo que se convertía en una entrada económica más.

En contraste con otros barrios de La Habana, desde lo arquitectónico y desde lo socioclasista, el Náutico emergió como un barrio de blancos, con poder económico, estructuralmente «cerrado», con un punto de control para las entradas y salidas, policía privada y una vida social estrechamente vinculada a los servicios que ofrecía el Club. Hoy, el Náutico continúa brindando una imagen de nivel socioeconómico alto, de la que se enorgullecen sus jóvenes. Un número importante de sus moradores ${ }^{4}$ están relacionados con las familias fundadoras del barrio o que han vivido en él por varias décadas; asimismo, se

3 Los Clubes Náutico de Marianao y Casino Español de La Habana, son hoy los Círculos Sociales Obreros Félix Elmuza y José Ramón Rodríguez, respectivamente.

4 El barrio tiene aproximadamente una población de 1.360 habitantes. 
reconoce como lugar de residencia de dirigentes del gobierno, deportistas, artistas y extranjeros (temporales o permanentes).

En este barrio se distingue, por sobre todas las cosas, la costa. No puede pensarse nada en él que no contemple el mar. En la costa se reúnen los jóvenes, que se reconocen como un sólo grupo, con la única condición de «ser del Náutico»; esta proximidad a la costa influye en una forma peculiar en su vestir, muy dada al uso de prendas de sport (short, camisetas, tenis), con la singularidad de ser productos patentados con marcas reconocidas a nivel mundial (Fila, Puma, Adidas, Lacoste, Reebook, Nike, Wilson) y alto costo en el mercado.

El parque es otro lugar importante, funciona como punto de encuentro, de reunión, de ahí pueden partir a otros lugares por ejemplo, a practicar deportes fuera del barrio, que es de lo que más hacen y que les gusta. Llama la atención que en este parque se reúnen infantes, adolescentes y jóvenes interactuando como un solo grupo y se aprecia que los de mayor edad manifiestan actitudes de compromiso y responsabilidad con los más pequeños.

A diferencia de otros barrios capitalinos, en el Náutico no se evidencian fuertes tradiciones culturales. La influencia cultural más notoria descansa en la vinculación al círculo social, al cual —actualmente - los jóvenes no siempre tienen acceso, dificultando su recreación.

POGOLOTTI: conservando su estructura de barrio netamente humilde, con alta presencia de clase obrera, se descubre al interior del municipio Marianao, con voz de pueblo, propio de su gente espontánea y sencilla, esta comunidad. Hijos de una historia particular, que marca con su sello la imagen y dinámica de este barrio hasta nuestros días. Fundado el 24 de febrero de 1911, Pogolotti ha trascendido en la historia nacional como el primer barrio obrero de La Habana, también del país e incluso, hay quien asegura que de América.

Actualmente, entre sus calles medianamente estrechas y desatendidas, se observa un cuadro pintoresco: casitas apiñadas con techos de tejas francesas, pequeños portales, limitados con cercas o muros de aproximadamente un metro, sin mayores adornos que la diversidad de colores con que se uniforman las paredes. El arquitecto Mario Coyula reconoce en este barrio habanero «el primer conjunto de vivienda social urbana en Cuba» (Coyula, 2004). De la misma manera que describe sus viviendas como «pequeñas unidades en tiras de una planta, con portal frontal corrido a lo largo de calles muy estrechas; una tipología tomada del pequeño pueblo cubano» (Coyula, 2004), pero que 
no han escapado a las iniciativas particulares de sus moradores y es posible observar ampliaciones y cambios en las fachadas, rompiendo con la arquitectura original.

Carente, antes de 1959, de servicios básicos de agua, electricidad, dificultades con las redes del transporte público y con la presencia, desde 1953, de un asentamiento poblacional «informal» en la zona sur de su territorio, conocido como la «Isla del Polvo», Pogolotti respira identidad; identidad que ha tenido que ser defendida ante el dedo acusador que lo señala — aún hoy — como barrio marginal, insalubre y violento.

En Pogolotti habitan todos los colores de Cuba. ${ }^{5}$ Basta con adentrarse por sus calles, tocar una puerta, entrar a una casa [...] o pararse en una esquina y observar cómo hablan, gesticulan, caminan y conviven los habitantes de un barrio que muy a pesar de la segregación social, el aislamiento y la falta de integración logística e infraestructural con el resto de la ciudad ha tenido que sortear no pocos escollos, para mantener vivo su sentido de pertenencia como comunidad (Trujillo, 2007:2).

Territorio caracterizado por un fuerte sincretismo religioso; deidades que reinan en los altares colocados en las esquinas de las salas: Santa Bárbara (Changó), la Virgen de las Mercedes (Obbatalá), San Lázaro (Babalú Ayé), la Virgen de Regla (Yemayá) y la Caridad del Cobre (Ochún), rodeadas por sus ofrendas y con velas encendidas a la espera de sus vísperas. Coexisten además, templos masónicos, iglesias bautistas, como Ebenezer, Regla de Ocha, Palo Monte y plantes abakuás. Sin dudas, la marcada presencia del factor religioso, sobre todo, el de los cultos africanos, ha influido en el carácter marginal con que se ha signado al barrio.

Otra de las tradiciones culturales de más arraigo popular son las celebraciones por el 24 de febrero, fecha de su fundación. A lo largo de 3 días $(22,23$ y 24), se realizan actividades culturales y gastronómicas en las que participan sus gentes sin distinción de edad, color o profesión. Mientras que en el decurso cotidiano es posible encontrar, a cualquier hora, en portales y esquinas improvisados tableros de dominó o juegos de tenis (canchas) en el complejo deportivo Jesús Menéndez. A la vez que al ritmo de las tumbadoras, se descubre un baile alrededor de un toque de santos.

En 1990, como respuesta comunitaria para paliar la crisis económica que recién comenzaba, en Pogolotti, como en otros barrios de La

5 No obstante, hay una presencia alta de población negra y mestiza. 
Habana, se creó el Taller de Transformación Integral del Barrio. ${ }^{6}$ Sus primeras acciones estuvieron dirigidas al mejoramiento de las viviendas del ya mencionado asentamiento «Isla de Polvo», experimento que no alcanzó los objetivos propuestos, y a la creación del grupo de baile afrocubano Alafia, potenciando elementos identitarios del barrio. El trabajo del Taller se fue consolidando y desde 1997 se realizan, con carácter anual, diagnósticos para determinar, según los vecinos, los principales problemas del territorio, las propuestas de solución y la prioridad de las mismas. En este sentido, emergen como focos de atención el estado crítico de las viviendas, el mal estado de sus calles, el alto índice de violencia y el consumo de estupefacientes.

Hoy una mirada a las dinámicas identitarias en los jóvenes de Pogolotti, precisa el tener en cuenta el recorrido histórico de los que lo reconocen como su caudal cultural. Pues si bien las realidades socioeconómicas que atraviesan sus vidas en la actualidad, matizan su interpretación del mundo y el cómo se visualizan en él, no es menos determinante el legado moral y ético de sus generaciones precedentes.

LA VÍBORA: al centro norte de la Ciudad de la Habana, enclavada en el más populoso de sus municipios, 10 de octubre, se erige el tradicional barrio de la Víbora, asentamiento poblacional que se ubica a finales del siglo XVII, y que si bien emergió como «un pueblo de blancos pobres, que se sustentaban del comercio, del tránsito y del cultivo de frutos menores y la venta de leche que llevaban a La Habana» (Pichardo, 2000:2), familias pudientes de la ciudad comenzaron la construcción de grandes casas de recreo o veraneo, que dotan al barrio de una riqueza arquitectónica muy peculiar, sobre todo, en las edificaciones ubicadas en la Calzada de Diez de Octubre, similares a las que podemos hallar por ejemplo, en la Calzada del Cerro.

El inicio del siglo XX, trae consigo otras construcciones que son en la actualidad referentes del barrio. Así tenemos que en 1906, Ángel Justo Párraga erige su majestuoso chalet Santa Isabel, hoy Casa de

6 Centro Comunitario que persigue solucionar, en la medida de lo posible, las problemáticas de la comunidad donde se encuentra enclavado, para estas soluciones necesita el apoyo de los vecinos. Son iniciativas desde y para el barrio. Generalmente los Talleres de Transformación Integral del Barrio cuentan con un grupo de profesionales de diversas disciplinas y reciben la orientación sistemática por parte del Grupo para el Desarrollo Integral de la Capital. 
Cultura del municipio mientras que la orden religiosa Los Pasionistas de la Habana, quienes dotan al territorio de su primera capilla católica en 1911, comenzaron la edificación en 1936 de la conocida iglesia Los Pasionistas, inagurada en 1948 y comúnmente llamada iglesia de la Víbora. También la población se diversificó. «Con la independencia de España, llegaron muchos inmigrantes españoles, polacos, hebreos, sirios, además de los chinos que habían llegado antes y todos establecieron variados negocios y comercios en la Víbora» (Pichardo, 2000:6). El transporte fue dejando atrás a los coches tirados por caballos, para dar paso a los tranvías eléctricos, lo que propició el aumento del tránsito por el territorio, hacia otros puntos de la ciudad.

Del entorno viboreño se destacan sus parques, sobre todo el de Cortina y el de los Enamorados, las discotecas «El Túnel» y «El Brindis», a la que no sólo asisten los adolescentes y jóvenes del barrio, sino también de otros territorios; la cultura encuentra interesantes propuestas los fines de semana en el Teatro Municipal Mariana Grajales y la Plaza Roja se erige como un espacio multipropósito donde tienen lugar actividades de carácter diverso: conmemorativas, militares, culturales y gastronómicas y se considera además, como un punto de referencia para los habitantes de este barrio.

La Víbora es el centro de la vida sociopolítica del municipio. En ella se hallan las sedes del Partido y la Unión de Jóvenes Comunistas y las Direcciones Municipales de Educación y Vivienda, así como la Oficina Provincial de Emigración. Desde el punto de vista económico, lo más relevante es la fábrica Cubana de Acero.

JeSÚS MARÍA: se ubica en el municipio de la Habana Vieja. Delimitado por las calles Monte, Egido, Desamparados, Diaria y Manglar, guarda en sus antiguas edificaciones la historia de sus primeros moradores. Este barrio, al decir de Fernando Ortiz: el más temeroso de extramuros, ha transmitido - hasta nuestros días - vestigios de lo que desde épocas anteriores lo ha caracterizado. De generación en generación, ha pasado su andar, su confraternidad, el sentido de pertenencia al barrio, la religión y su condición de marginal.

En esta zona se asentaron los «negros curros», que constituyeron su primer núcleo poblacional, originando un humilde caserío confeccionado de guano, yaguas y piso de tierra. Se distinguieron por la forma de su lenguaje, lo llamativo de sus vestidos y adornos; por sus andares peculiares, desafiantes, la mala vida de crímenes y envalentonamiento, siempre armados de cuchillo y en actitud retadora. Eran 
vistos como parásitos sociales que nada producían y su sustento económico estaba en la delincuencia y la prostitución, por lo cual con frecuencia se les tachaba de chulos, rufianes en sus tratos con la mujeres de «la vida» y muy particularmente con la negra curra que compartía, junto a ellos, las aventuras de su mala vida. Este modo de vida desarrollado en la etapa colonial, siguió siendo similar durante la neocolonia. La historia de Jesús María lo reconoce como uno de los barrios más pobres de la ciudad, arrastrando males como la esclavitud, la miseria, el analfabetismo, el hacinamiento, la promiscuidad y el juego, como expresiones fundamentales de subsistencia. Algunos de estos males se han arraigado hasta nuestros días, moldeando los comportamientos de los habitantes del lugar.

Jesús María es un barrio de fuertes tradiciones culturales. A su natural alegría se une la afición por la rumba y la presencia, en sus festividades, de la comparsa «La jardinera», integrada por mujeres del lugar y las flores naturales como elementos decorativos. La religión se erige como un rasgo distintivo del barrio; hay un predominio de la religión yoruba con asentamientos espontáneos de juegos abakúa y presencia de las religiones católica y protestante, evidenciando el sincretismo religioso del lugar por ejemplo, es habitual que al pie de las tres majestuosas ceibas que custodian la entrada de la iglesia católica, se hallen las ofrendas y «trabajos» de los practicantes de las religiones afrocubanas.

Su problemática social es compleja, teniendo en cuenta que la principal dificultad es el deterioro y mal estado de la vivienda, en parte generador de conflictos que inciden en la disfuncionalidad de la familia y en los comportamientos inadecuados de niñas, niños, adolescentes y jóvenes en los centros de enseñanza y en la propia comunidad. [...] A esto se suman condiciones de alta vulnerabilidad social como la violencia, el alcoholismo, la prostitución y la drogadicción (Colectivo de Autores, 2006:68).

Respecto a las viviendas, actualmente «el territorio está totalmente urbanizado, con construcciones de estilo neoclásico, adaptado a los gustos y posibilidades de su población, de origen muy popular. Los tipos de viviendas más frecuentes son: edificios múltiples, ciudadelas y viviendas individuales con altos índices de deterioro» (Colectivo de Autores, 2006:68).

Otra de las particularidades del barrio son los vendedores de esquinas. Tal vez pudiera pensarse en una proliferación de estos en las 
calles habaneras, sin mucha distinción entre los barrios; la especificidad de Jesús María radica en la venta - a plena luz del día y con la mayor impunidad - de objetos que tienen forma de destornilladores, pero si nos acercamos un poco veremos que son afilados y punzantes, y que son utilizados para darle el «toque final a las fiestas del lugar».

Este barrio capitalino ha contado con el apoyo del Programa de Desarrollo Humano Local de las Naciones Unidas y de la ONG Save the Children, Reino Unido que, conjuntamente con las autoridades del territorio e instituciones científicas cubanas como el Instituto Central de Ciencias Pedagógicas y el Centro de Estudios Sobre la Juventud, han puesto en práctica proyectos comunitarios que han dado origen a instituciones como: el Taller de Transformación del Barrio, La Casa del Niño y la Niña, que comparte el espacio con la anterior, la Ludoteca Pinocho, la Unión Fraternal y el Taller de Oficios, todas ellas con el objetivo común de colaborar en la transformación adecuada de la comunidad.

GUAICANAMAR: ${ }^{7}$ frente al mar, como su nombre aborigen lo indica, se erige el Consejo Popular de Guaicanamar, uno de los dos en los que se divide administrativamente el ultramarino pueblo de Regla. A diferencia de los otros barrios que tributan a este estudio, su historia se entremezcla con la historia de Regla, tal vez por ello no nos extrañe que los jóvenes de hoy nos digan: «no nos hable de barrios, háblenos de Regla», o que alguien imprescindible para la Cultura Nacional como Humberto Medina, fundador de la emblemática comparsa Los Guaracheros de Regla, afirme:

los habitantes de este territorio tienen un gran arraigo a las costumbres y tradiciones del pueblo y un elevado sentido de pertenencia a su terruño y se sienten orgullosos de haber nacido en Regla, lo que los identifica y los diferencia del resto de los habaneros, por lo que en ocasiones se les tilda de regionalistas, cuando en realidad son celosos defensores de su cultura y de su historia (Almenares, 2005:21-22).

7 Regla ofrece la particularidad, de que su población juvenil no se siente parte de un barrio determinado. El eje territorial que atraviesa el sentido de pertenencia de los reglanos se circunscribe al tradicional pueblo de Regla. Para nuestro estudio, determinamos encuestar a jóvenes pertenecientes al Consejo Popular Guaicanamar, donde se desarrolla con más fuerza la vida sociopolítica del territorio y que además, geográficamente, responde al núcleo que dio origen al pueblo. 
La singular historia de este territorio, se remonta a nuestros primeros pobladores (1573) y se vincula también a la Virgen de Regla. Los apuntes históricos sobre este particular nos remiten a Pedro Recio de Oquendo, quien el 3 de marzo de 1687, hace donación de una porción de tierra a un personaje llamado Manuel Antonio, conocido como El Peregrino, quien se proponía erigir una ermita a Nuestra Señora de Regla. Desde entonces, y hasta el 8 de septiembre de 1694, en que el castellano Jefe de la Fortaleza Militar de la Punta, Don Pedro Aranda de Avellaneda, trajera de España la imagen que hoy se venera, se adoró un cuadro pintado al óleo. A partir de este momento, fue creciendo la devoción por la virgen morena y se fue asentando el pueblo alrededor de la ermita. Las fechas referidas marcan, la fundación del poblado y el Día de la Virgen de Regla, considerada patrona de la Bahía de La Habana desde 1714. El actual templo fue construido en 1811; en marzo de 1987 fue declarado Monumento Nacional y a finales de ese mismo año se le reconoció como Santuario Nacional.

La otra cara de la moneda nos la ofrece el sincretismo vivo, que fluye como prueba del torrente cultural de los pueblos y su historia. La patrona del municipio, del mar y los marineros, «es también la Yemayá del panteón Yoruba, hermana de Ochún y madre de la vida y todos los Orischas y por ello no es raro ver cada 8 de septiembre, en su fiesta, que es la fiesta del pueblo, su imagen adornada con encendidas velas y en las afueras del templo encontrar los ebbó que dejan los creyentes de los cultos afrocubanos como ofrendas y muestras de sacrificio y purificación» (Almenares, 2005:6). Confirmación de la vigencia de esta cultura, fundamentalmente negra, es la presencia de los ñáñigos o abakuás. A este territorio, le cabe el privilegio que en 1836 se fundara, por negros esclavos procedentes de los calabares y del sur de Nigeria, la primera sociedad secreta abakuá en Cuba (Efik Butón); perseguidos sus miembros, incluso proscrita en algún período, se han mantenido. En Regla se afirma que hoy existen 26 juegos o potencias, y cuenta con gran atención y respaldo por parte de los jóvenes reglanos.

Desde su surgimiento, Regla ha sido un poblado con un desarrollo económico muy marcado, que ha influido en el carácter eminentemente obrero de sus habitantes; sin desestimar la fuerte presencia de mano de obra esclava, tanto africana como china, en el período colonial. Se habla de un $41 \%$ del territorio urbanizado y el resto ocupado por instalaciones industriales, portuarias, militares y áreas verdes.

El desarrollo del transporte es también muy peculiar. Una historia de movimiento marítimo desde el siglo XVI, que cristalizó en la cons- 
trucción en 1912 de una terminal de ferries o lanchas para la transportación de pasajeros de un lado a otro de la Bahía es el origen de la todavía hoy muy popular «lanchita de Regla». También fue uno de los primeros pueblos que contó con servicio de tranvía.

Otros lugares tradicionales de la ciudad mágica — como la nombró Alejo Carpentier - son el Liceo Artístico y Literario, inaugurado en 1878, con el orgullo de contar entre sus primeros socios a José Martí. En este lugar aún se celebran los bailes más antiguos del territorio: el de las Flores, en mayo y Noche azul, en septiembre y se alza la Colina Lenin o Loma del Fortín, lugar donde se dice que por vez primera se le rindió homenaje al líder de la Revolución de Octubre y se celebró el primer acto oficial por el $1^{\circ}$ de Mayo, tradición que continúa en nuestros días.

Las calles también merecen su aparte. Responden todas a nombres de mártires, personalidades del territorio y fechas históricas. El reglano te dice: «soy de Martí», «soy de Agramonte»..., así se identifican. Otro rasgo distintivo es que no caminan por las aceras, sino por el medio de la calle.

No se puede hablar de la historia cultural más reciente de este terruño sin hacer alusión a la archiconocida comparsa: Los Guaracheros de Regla, constituida en 1959 por un grupo de jóvenes reglanos; esta institución ha logrado trascender a través de varias generaciones, los límites estrechos de un pueblo, para convertirse en una auténtica expresión de la cultura popular de una nación.

Los jóvenes son fanáticos del béisbol, promovido desde las calles, no se inclinan por asistir al Video Club Juvenil, lo contrario ocurre con el Joven Club de Computación; los dos cines del territorio están cerrados, el Liceo no cubre sus expectativas de recreación, y el deplorable estado constructivo de la Casa de la Cultura, ha dado al traste con el amplio movimiento de aficionados, fundamentalmente de jóvenes, que existía en el Consejo y en el pueblo.

\section{Resultados}

Llegado a este punto, y ante la imposibilidad de poder realizar en estas páginas un análisis pormenorizado de los resultados obtenidos, expondremos una integración de los aspectos que, a nuestro juicio, resultaron más interesentes y - sobre todo- válidos en correspondencia con los propósitos de la investigación. Así tenemos que: 
i) Las características identitarias de los jóvenes resumen que todos los encuestados, con independencia de los barrios donde habitan, tienen una identidad que guarda puntos de coincidencia, lo que demuestra una unidad en torno a la identidad nacional, juvenil y como capitalinos. Esto puede ser percibido en las siguientes observaciones.

Los jóvenes conviven con sus familias de origen, y aunque la mayoría cuenta con un espacio personal dentro de sus viviendas, se manifiestan contradicciones y conflictos asociados a la intolerancia por parte de los adultos por formas vestir, comportamientos, expresiones verbales, accesorios de moda, gustos musicales y decoración de los espacios de los jóvenes, lo que influye en la construcción identitaria.

Los valores contenidos en la identidad juvenil más reforzados por la familia, en orden de prioridad son: honestidad, respeto, solidaridad, laboriosidad y patriotismo. Los mismos tienen una tradición en nuestra identidad nacional, aunque para los jóvenes los que se relacionan con este último (antiimperialismo e independentismo) son menos reconocidos no obstante su significación para el sostenimiento del proyecto social cubano.

Los jóvenes encuestados se sienten orgullosos de ser cubanos, e identifican como razones principales de ello: la cultura, el arte y el idioma del país, las particularidades que tradicionalmente se han ido naturalizando en el imaginario de ser cubano y nuestra historia.

Los jóvenes capitalinos estudiados se autoperciben —básicamentealegres, críticos, revolucionarios, responsables, decididos y sensibles y también como promiscuos, vagos y desorganizados. De la misma manera, la juventud se asocia a la posibilidad de realizar actividades tradicionalmente «mistificadas» para la edad juvenil, proporcionándole placer y bienestar, lo que les hace sentirse complacidos con su condición de joven. Ello permite afirmar que uno de los resortes de su identidad descansa en la asunción de lo que socialmente se ha concebido para esa etapa de la vida. La imagen que tienen los jóvenes de sí mismos pasa por el prisma de las creencias, estereotipos y verdades que se manejan hoy en el imaginario social de los cubanos y que ellos reproducen, a veces acusadoramente y otras sin cuestionamientos.

La identidad de los jóvenes con su barrio se sustenta fundamentalmente por el tiempo de residencia y las especificidades de la población que habita en ellos. Existen otros aspectos del barrio (arquitectura, limpieza, calidad y cantidad de sus servicios, dinámicas comunitarias, lugares recreativos y funcionamiento de las organizaciones de masas), que no siempre constituyen pilares de esa identificación. Las 
diferencias de las identidades barriales se asocian a las características específicas de los territorios.

Si bien hay una mayoría de jóvenes que no han pensado mudarse o irse a vivir permanentemente a otro lugar, no es desestimable el valor que alcanza los que sí piensan hacerlo y dentro de estos, los que declaran otro país como destino. Las razones de su emigración, están más asociadas a las necesidades para concretar sus proyectos de vida, o a las necesidades para satisfacer exigencias propias de la edad (recreación y vivienda fundamentalmente), que a contenidos políticos declarados o a la no identificación con lo nacional.

La identidad juvenil está atravesada por la situación económica, lo que se expresa por las fuentes de manutención (proveniente de otros familiares y los ingresos del trabajo estatal) y por la satisfacción de las necesidades (la mayoría y las más apremiantes).

Los jóvenes manifiestan sentido de pertenencia a los grupos que cotidianamente conforman sus sistemas de relaciones y redes de apoyo: familia, grupo escolar o laboral y comunidad. Para algunos jóvenes, la edad en sí misma ha sido objeto de exclusión en el barrio, de la misma manera, que características muy propias de la edad juvenil, como la afiliación a tendencias musicales y de la moda, han sido objeto de rechazo por parte de otros jóvenes o generaciones.

ii) Las características de los barrios seleccionados, en cuanto a su nivel socioeconómico y otras como: tradiciones culturales e históricas, arquitectura o infraestructura, clima sociopsicológico imperante o dinámicas educativas y de relaciones, influyen en la construcción de la identidad juvenil, delimitando la existencia de subidentidades particulares. Aunque todos los jóvenes comparten características identitarias como grupo, este eje territorial atraviesa y origina diferencias entre ellos (mismidad y otredad). Las consideraciones que aparecen a continuación así lo demuestran.

Los jóvenes de Jesús María habitan fundamentalmente en casas y cuarterías, y conjuntamente con los de Pogolotti, sus viviendas se hallan en peor estado en comparación con el resto. Esto genera sentimientos de inferioridad o exclusión por un lado, y superioridad $\mathrm{u}$ orgullo de su entorno por otro, fundamentalmente dados los significados que cada uno le otorga a su espacio barrial y las relaciones interpersonales que estos significados crean.

La honestidad es un valor que ocupa el primer lugar para los jóvenes del Náutico, Guaicanamar y Pogolotti, mientras que para los de 
la Víbora es la solidaridad y para los de Jesús María es el respeto, lo cual está muy ligado a las tradiciones culturales de los territorios.

Los jóvenes del Náutico sobresalen al esgrimir con mayor fuerza, entre las razones de identificación su barrio, el nivel socioeconómico y algunos elementos asociados a su geografía y urbanización, lo que se corresponde con las características del territorio. Los de Jesús María y Pogolotti, priorizan las tradiciones culturales, típicas de su entorno, y la participación sociopolítica que de alguna manera se relaciona con ser los únicos estudiados que cuentan con un Taller de Transformación Integral del Barrio. Los reglanos, por su parte, refuerzan la percepción colectiva de los habitantes de la capital sobre su fuerte identificación con las tradiciones de este terruño.

En Jesús María se expresa, como aspecto positivo, ser un barrio trabajador, pero a esto le otorgan un significado asociado a la lucha por la sobrevivencia cotidiana. Guaicanamar resalta las tradiciones culturales; mientras la Víbora y el Náutico comparten la opinión de vivir en un barrio tranquilo y seguro. En el Náutico es donde único no se manifiestan aspectos asociados al orgullo de ser cubanos.

Los jóvenes de la Víbora, Pogolotti y Jesús María coinciden en listar como características negativas de sus barrios: el alto índice de delincuencia, los desórdenes públicos y la violencia. Otras coincidencias las ofrecen el Náutico y Guaicanamar con relación a la insuficiencia de centros recreativos; y Jesús María y la Víbora con relación a la suciedad existente en sus espacios. Hay cuestiones que resultan privativas de uno de los barrios, como puede ser lo aburrido para el Náutico.

Aunque la imagen que tienen estos jóvenes de sí mismos es similar en todos los barrios, el Náutico se destaca porque sus jóvenes mencionan características negativas que no esgrimen los demás, como son: deshonestos, no estudiosos y superficiales. Así mismo, solo en Pogolotti se dice que los jóvenes cubanos son mal educados y en Guaicanamar que también son profundos. Por otra parte, Jesús María es el barrio donde menos cualidades positivas se reconocen en los jóvenes.

El nivel de jerarquía en que se ubican las razones de orgullo de ser cubano difiere entre los barrios, lo que indica que los significados cambian y con ello también las prioridades que se conceden. Otras razones se hallan ausentes en la expresión de los jóvenes, como es el caso de «nuestra independencia» para los de Guaicanamar y Pogolotti, los «éxitos deportivos» para los de este último y Náutico y «nuestra historia» para los de la Víbora. 
El potencial migratorio en Pogolottí y Jesús María se expresa más alto que en el resto de los barrios, mientras que en Guaicanamar y Náutico se manifiesta bajo. Sólo en la Víbora el destino no es otro país, sino otro municipio o barrio. Así mismo, en cuanto a las razones para emigrar, los jóvenes de Jesús María y Náutico expresan la insuficiente recreación, aunque las interpretaciones a partir de las características de los territorios cambian. En la Víbora y Guaicanamar se plantean los problemas de vivienda y en Pogolotti, los conflictos sociales.

Entre los jóvenes que han vivenciado exclusión en determinadas ocasiones, los de la Víbora, Pogolotti y Jesús María plantean como principales causas, la edad. Los encuestados de estos dos últimos barrios manifiestan haber sentido rechazo fundamentalmente por el color de la piel y en el caso de Jesús María también por el nivel socioeconómico bajo. Así mismo, los del Náutico expresan sentirse despreciados por sus gustos musicales y los de Guaicanamar por pertenecer a organizaciones políticas.

iii) El análisis realizado en algunas variables demuestra que los ejes tradicionales sociodemográficos repercuten en el proceso de construcción de la identidad que, a lo interno de los jóvenes, se traducen en diferencias a partir del género, color de la piel, ocupación, lugar de residencia, entre otros que también marcan la existencia de sus identidades.

iv) En las características identitarias de los jóvenes se reproducen estereotipos y representaciones sociales que son comunes a otras generaciones, como por ejemplo: las asociadas a la forma de ser de los cubanos. A la vez, se han ido legitimando otras con particular incidencia en sus proyectos de vida y que transgreden concepciones fuertemente arraigadas en nuestra sociedad, pero que además, están en correspondencia con las tendencias internacionales, es el caso de priorizar las uniones consensuales sobre los matrimonios o la asunción de la moda relacionada con los gustos musicales.

LA HABANA (CUBA), SEPTIEMBRE 2009

RECIBIDO: SEPTIEMBRE 2009

ACEPTADO: OCTUBRE 2009 


\section{REFERENCIAS BIBLIOGRÁFICAS}

Almenares, Fernando (2005): «Programa Literario Cultural (Proyecto). Regla: la ciudad mágica de ultramar. Historia y tradiciones». Trabajo de Diploma, Curso Superior de Turismo, Escuela de Hotelería y Turismo de Playas del Este.

BARREAL FERNÁNDEZ, ISAAC (1991): Estudios etnosociológicos. La Habana: Editora Pensamiento Cubano, Ciencias Sociales.

Colectivo de Autores (2006): «La casa del niño y la niña de Jesús María. Una propuesta de desarrollo humano local». Revista Estudio N$^{\circ} 5$. La Habana: CESJ.

COYUla, MARIO (2004): «Campeando en la ciudad». Revista Revolución y Cultura $\mathrm{N}^{\circ} 3$, Época V. La Habana: Ministerio de Cultura.

De la Torre, CARolina (2001): Las identidades. Una mirada desde la psicología. La Habana: Centro de Investigación y Desarrollo de la Cultura Cubana Juan Marinello.

DAYRELL, JUAREZ (2005): «Juventud, grupos culturales y sociabilidad». JOVENES, Revista de Estudios sobre Juventud $\mathrm{N}^{\circ} 22$. México: Instituto Mexicano de la Juventud (IMJ).

IÑIGUEZ, LUISA (2004): «Desigualdades espaciales en Cuba: entre herencias y emergencias». En Heterogeneidad social en la Cuba actual. La Habana: Universidad de La Habana, Centro de Estudios de Salud y Bienestar Humano.

Marcial, Rogelio (1996): Desde la esquina se domina. Grupos juveniles: identidad cultural y entorno urbano en la sociedad moderna. Guadalajara: El Colegio de Jalisco.

Pichardo, OfElia (2000): «La Víbora: historia y leyendas». Ponencia presentada en el V Encuentro de Historia y Estudios Socioculturales, Museo Municipal Diez de Octubre, La Habana.

SANDOVAL, MARIO (2003): «La relación entre los cambios culturales y la participación social y política de los jóvenes». Teología y Pastoral para América Latina. Vol. XXIX, N¹13. Bogotá: ITEPAL.

Torres Cuevas, Eduardo y Oscar loyola Vega (2001): Historia de Cuba 1492-1898. Formación y liberación de la nación. La Habana: Editorial Pueblo y Educación.

TRUJILLO, IDANIA (2007): «Pogolotti: entre la historia y la leyenda». Boletín Caminos. Centro Memorial Martin Luther King, Jr. 